\title{
Kisspeptin Promotes Glioblastoma Cell Invasiveness Via the Gq-PLC-PKC Pathway
}

\author{
TAE-HUN KIM, JI HYE YOON and SUNG-GOOK CHO
}

Department of Biotechnology, Korea National University of Transportation, Chungbuk, Republic of Korea

\begin{abstract}
Background/Aim: Kisspeptin produced from the KISS1 gene is secreted from the living cells, binds to endogenous receptor KISSIR (also called G protein-coupled receptor 54, GPR54), and has various functions in normal physiological conditions. Although an anti-metastatic role of kisspeptin in cancer is well known in several cancer types, its role in brain tumors is not yet understood. Herein, we investigated a the role of kisspeptin in glioblastoma cells. Materials and Methods: Glioblastoma cells were treated with kisspeptin and subjected to proliferation, migration, and invasion assays. KISSIR dependency was tested by KISSIR silencing with KISS1R siRNAs. Results: Kisspeptin inhibited migratory and invasive abilities of U87-MG, U-251-MG and U373-MG glioblastoma cells with no effect on cell viability. KISSIR gene silencing with KISSIR siRNAs blocked kisspeptininduced glioblastoma cell invasiveness. Moreover, chemical inhibitors against Gq, PLC or PKC blocked kisspeptin-induced glioblastoma cell invasiveness. Conclusion: Kisspeptin induces glioblastoma cell invasiveness via the KISSIR-Gq-PLC-PKC signaling pathway.
\end{abstract}

Glioblastoma, type IV astrocytoma or glioblastoma multiforme, occurs in the brain or spinal cord, and originates from abnormal astrocytes (1-4). Although surgery, radiotherapy and and drug treatment are applied to treat glioblastoma, high-grade glioblastomas are not well treated and supportive care is rather considered (2, 5-7). For example, type IV glioblastoma multiforme is resistant to temozolomide, while type III glioblastoma is sensitive to it $(6,8-12)$.

Kisspeptin produced from the KISSI gene is secreted from cells, binds to endogenous receptor KISS1R (also called G protein-coupled receptor 54, GPR54), and plays multiple

Correspondence to: Sung-Gook Cho, Department of Biotechnology, Korea National University of Transportation, Chungbuk, Republic of Korea. Tel: +82 438205254, Fax: +82 428205272, email: chosg@ut.ac.kr

Key Words: Glioblastoma, kisspeptin, KISS1, KISS1R, brain tumor. roles in normal physiological conditions, thereby being applied for treating abnormalities (13-16). It has been well known to regulate the onset of puberty and inhibit cancer metastasis (16-19). Moreover, kisspeptin-mediated signaling has been revealed to regulate circadian rhythm, appetite and reproduction $(13,15,19-23)$. Kisspeptin is known to regulate KISS1R-Gq/11-PLC-PKC pathway in the brain, although we still need more knowledge for kisspeptin-mediated signaling networks $(17,18,20,22-24)$. Likewise, kisspeptin regulates this KISS1R-Gq/11-PLC-PKC signaling pathway in the inhibition of cancer metastasis $(17,18,20)$.

Kisspeptin is on clinical trials to solve problems in either fertility or puberty $(13,15-17)$. A therapeutic drug design is also considered on the basis of its anti-metastatic role (2527). Kisspeptin inhibits cancer cell proliferation, migration and invasion in dependence of cancer cell types $(17,20)$. Moreover, kisspeptin blocks VEGF-induced tumor angiogenesis by inhibiting FAK in endothelial cells (28). However, kisspeptin-mediated signaling is likely to be required in the in vivo breast cancer model systems (29). Consistently, kisspeptin was reported to accelerate the invasiveness of highly metastatic triple-negative breast cancer cells $(30,31)$. Therefore, understanding its biological role in cancer is urgent in order to decide if such treatment schedules are applicable in the clinic (13, 21, 25-27, 32, 33).

Knowledge for an anti-metastatic role of kisspeptin in cancer is well introduced in different cancer types, although its role in brain tumor is yet reported $(17,18,34)$. Considering its anti-metastatic role, we focused on its role in highly aggressive type IV glioblastoma multiforme. Interestingly, we found that kisspeptin accelerates the metastatic ability of glioblastoma cells representing type IV glioblastoma multiforme via its well-known G proteincoupled receptor (GPCR) pathway. Brain tumor cells do not express endogenous kisspeptin. As exogenous kisspeptin stimulated endogenous KISS1R-mediated intracellular signaling pathways in brain tumor cells, we could assume that endogenous kisspeptin from other regions of the brain could activate tumoral KISS1R and regulates brain tumor invasiveness. 


\section{Materials and Methods}

Cell culture and reagents. U87-MG, U-251-MG and U373-MG cells were kindly received from Dr. Sun-Ha Paik at Seoul National University Medical Center, Seoul, Korea. All cells were cultured in DMEM supplemented with $10 \%$ FBS and $1 \%$ Pen/Strep antibiotics. Kisspeptin-10 (YNWNSFGLRF-NH ${ }_{2}$ ) was purchased from Anaspec (Fremont, CA, USA). Gq inhibitor YM-254890 was obtained from Focus biomolecules (Plymouth Meeting, PA, USA). PLC inhibitors D609 and U73122 were purchased from Tocris (Minneapolis, MN, USA). PKC inhibitor bisindolylmaleimide III was purchased from Cayman (Ann Arbor, MI, USA).

Cell studies. A total of $1 \times 10^{4}$ cells were cultured on 96 well plates and subjected to WST assays (Dogen, Seoul, Republic of Korea). In addition, we conducted trypan blue assays to confirm cell growth by manually counting viable cells. Each experiment was conducted in triplicate and independently repeated three times. For cell migration, $1 \times 10^{5}$ cells were cultured on 6 well plates, followed by scratching using yellow tips and washing with PBS twice. After a 24-h scratching, cells which migrated onto scratched regions were counted. Experiments were duplicated and independently conducted in triplicate. For cell invasion, $1 \times 10^{4}$ cells were settled in chambers with matrigel-precoated $8-\mu \mathrm{m}$ pore polyester membrane (Corning, NY, USA) and cultured in no serum medium. Twenty-four-well plates at bottom were filled with $10 \%$ serum medium. Cells invaded into matrigel were stained with $0.5 \%$ crystal violet solution and counted manually. Experiments were conducted in triplicate. KISSIR siRNAs for KISSIR gene silencing and control siRNAs were purchased from Santa Cruz Biotechnology (Dallas, TX, USA). KISS1R gene silencing was conducted by manufacturer's instruction. In brief, $1 \times 10^{6}$ cells were transfected with siRNAs for $12 \mathrm{~h}$ and then subjected to the appropriate experiments.

Western blots. A total of $3 \times 10^{6}$ cells were lysed with radioimmunoprecipitation buffer for $30 \mathrm{~min}$ on ice and centrifuged at $20,000 \times \mathrm{g}$ for $10 \mathrm{~min}$ at $4^{\circ} \mathrm{C}$. Protein concentration was measured with the Pierce BCA protein assay kit (Thermo Fisher Scientific, Rockford, IL, USA) according to the manufacturer's protocol. A total of $30 \mu \mathrm{g}$ of protein was loaded on $10-12 \%$ SDSPAGE and transferred to polyvinylidene difluoride membrane (GE Healthcare Life Sciences, Piscataway, NJ, USA). Membranes were blocked with 5\% milk for $1 \mathrm{~h}$ at room temperature and incubated with appropriate antibodies for $1 \mathrm{~h}$ at room temperature. Protein bands were detected with LumiGLO chemiluminescent reagent and peroxidase (Cell Signaling Technology, Danvers, MA, USA). Antibodies for KISS1 and KISS1R were purchased from Abcam (Cambridge, UK). Antibodies for $\mathrm{PKC} \alpha / \beta$ and actin were purchased from Cell Signaling Technology (Danvers, MA, USA). Horseradish peroxidase (HRP)-linked anti-rabbit IgG or antimouse IgG antibody was used as a secondary antibody in dilution $1: 10,000$.

Statistical analysis. Unpaired Student's $t$-test or one-way analysis of variance with a post-hoc Tukey's test was performed to calculate the statistical significance of the results. Data were expressed as the mean \pm standard deviation, and $p<0.05$ was considered to indicate a statistically significant difference. Calculations were performed using SPSS version 22 software (IBM Corp., Armonk, NY, USA).

\section{Results}

Kisspeptin induces glioblastoma cell invasiveness in vitro. To investigate kisspeptin effect on highly aggressive grade IV glioblastoma, we examined kisspeptin effect on glioblastoma cell migration. When U87-MG, U-251-MG or U373-MG cells were scratched and then treated with kisspeptin at $100 \mathrm{nM}$ for $24 \mathrm{~h}$, kisspeptin increased cell migration by approximately $65 \%, 80 \%$ and $45 \%$, respectively (Figure 1A). Furthermore, kisspeptin increased migrated cell numbers even under no serum condition by about 35 60\% (Figure 1B).

Accordingly, we examined kisspeptin effect on glioblastoma cell invasiveness. When kisspeptin at $100 \mathrm{nM}$ was added on the upper chamber where the cells were cultured, kisspeptin treatment for $16 \mathrm{~h}$ increased the invaded cell number by approximately 30 55\% (Figure 1C). However, the invasion was not promoted when kisspeptin was added in the bottom chambers (Figure 1C), indicating that kisspeptin did not induce the invasion of glioblastoma cells by chemotactic attraction.

Next, when U87-MG, U-251-MG and U373-MG cells were treated with kisspeptin for $48 \mathrm{~h}$, kisspeptin did not significantly affect the viability of those cell lines (Figure 1D). Moreover, we failed to find its synergistic effect with temozolomide, when cells were co-treated with kisspeptin and temozolomide (data not shown).

Kisspeptin induces metastatic abilities of glioblastoma cells through KISS1 receptor, KISSIR. Kisspeptin, encoded from the KISSI gene and released from cells by post-translational modifications, is known as an endogenous ligand for Gprotein-coupled receptor 54 (GPR54; also named KISS1 receptor, KISS1R) (35-37). To test whether kisspeptin requires its receptor for the induction of metastatic abilities, we examined protein expression levels of both KISS 1 and KISS1R in U87-MG, U-251-MG or U373-MG cells. All glioblastoma cell lines only expressed KISS1R (Figure 2A).

Next, U87-MG, U-251-MG or U373-MG cells were transfected with KISS1R siRNAs or control siRNAs, to answer kisspeptin dependency of KISS1R. Silencing of $K I S S 1 R$ gene expression was confirmed by KISS1R blotting (Figure 2B), and the cells were subjected to the invasion assays. KISSIR gene silencing blocked kisspeptin-induced cell invasion (Figure 2C). Thus, our data indicate that kisspeptin requires KISS1R in the induction of glioblastoma cell invasiveness.

Kisspeptin induces metastatic abilities of glioblastoma cells by activating the Gq-PLC pathway. It has been known that kisspeptin-activated KISS1R mediates Gq activation (36-38). To examine whether kisspeptin-induced glioblastoma cell invasiveness requires $\mathrm{Gq}$ activation, U87-MG cells were pre- 
A

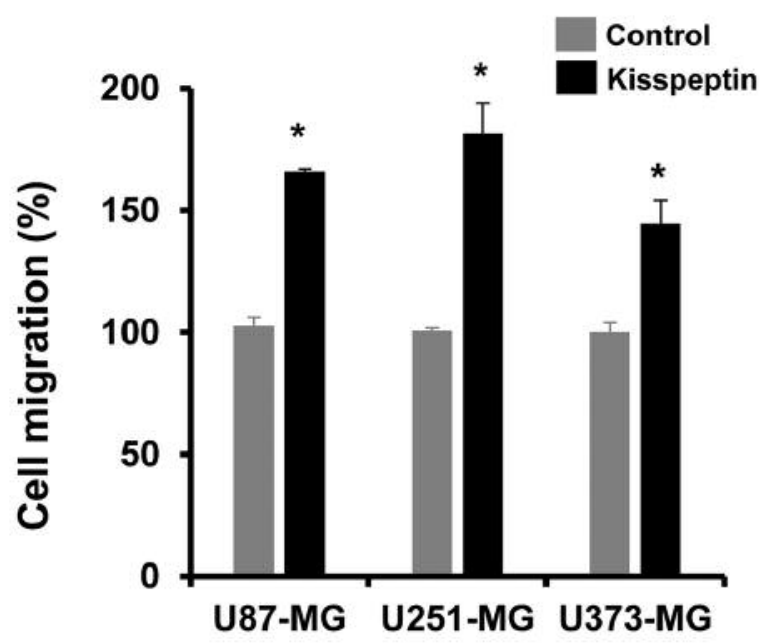

B

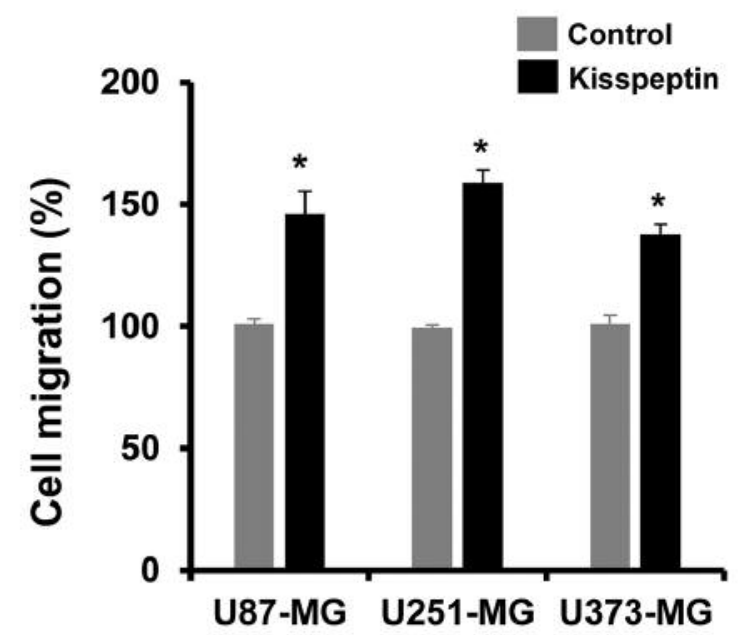

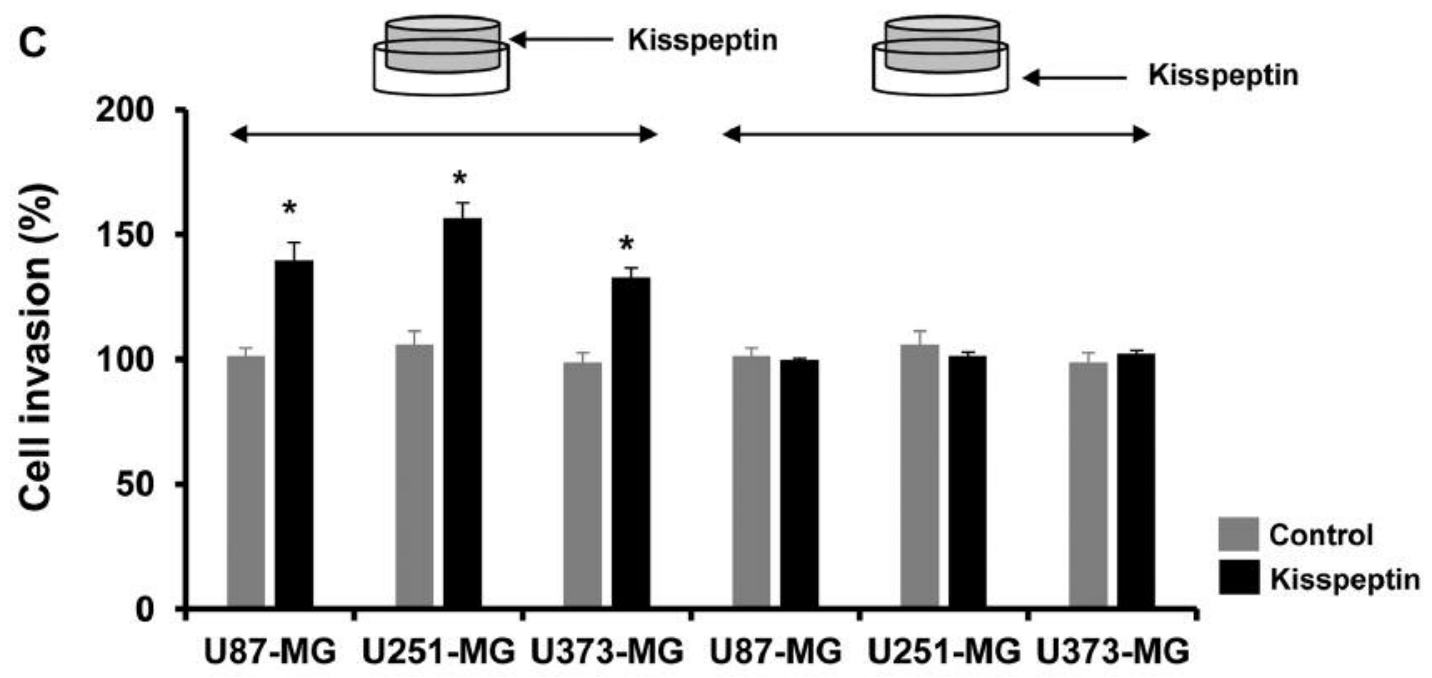

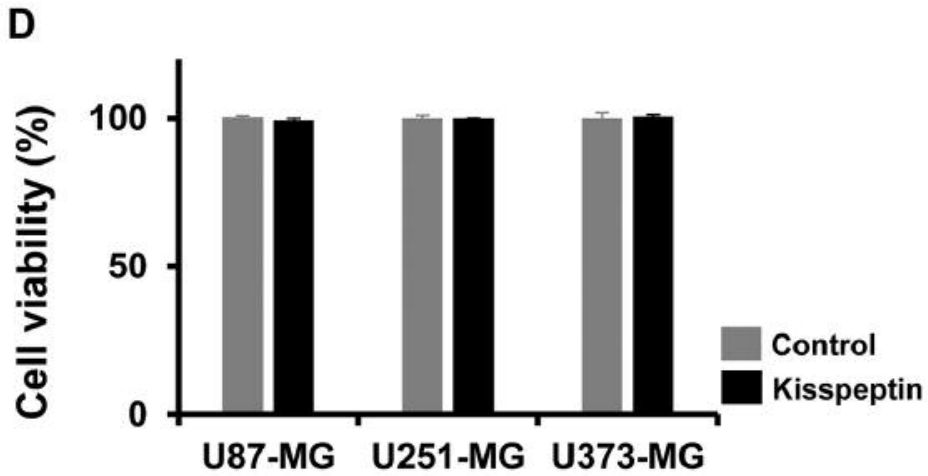

Figure 1. Kisspeptin induces migratory and invasive abilities of brain tumor cells. (A) Kisspeptin-induced migration of brain tumor cells in complete medium. (B) Kisspeptin-induced migration of brain tumor cells in serum-depleted medium. (C) Kisspeptin-induced invasion of brain tumor cells. (D) Kisspeptin did not affect brain tumor cell viability. ${ }^{*} p<0.05$. 
A

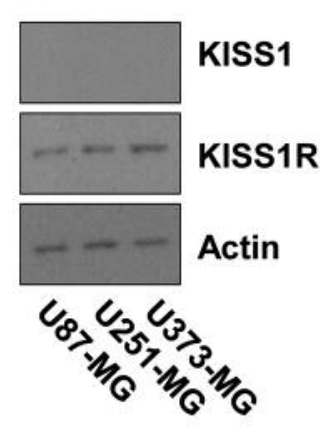

B

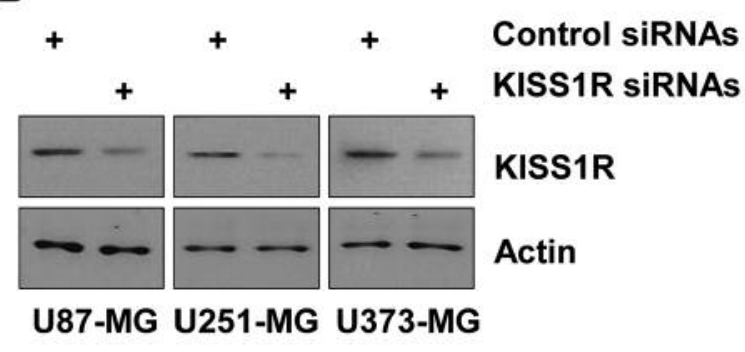

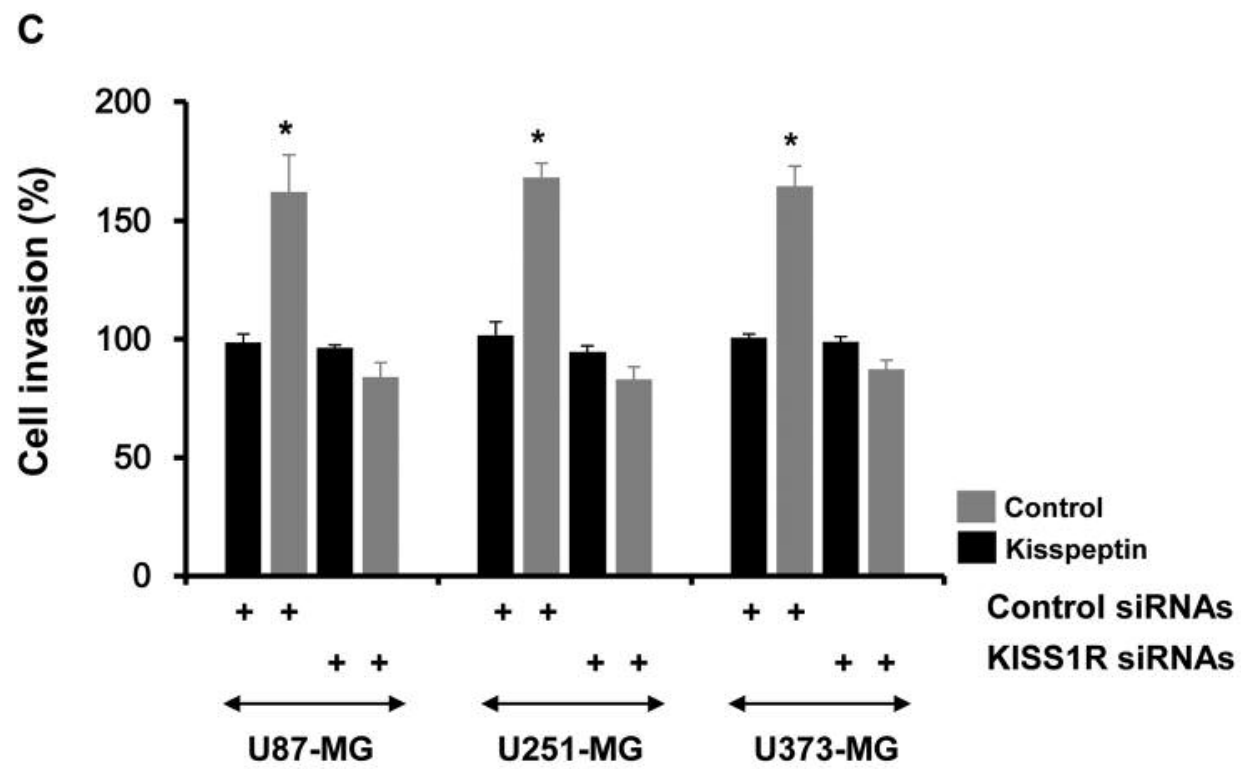

Figure 2. Kisspeptin induces brain tumor cell invasion via KISS1R. (A) Protein levels of KISS1 and KISS1R in brain tumor cells. Actin was used as an internal control. (B) KISS1R silencing with KISS1R siRNAs was confirmed by KISSIR western blotting. (C) KISS1R gene silencing inhibits brain tumor cell invasion $(D) . * p<0.05$.

treated with Gq inhibitor, YM-254890, and then treated with kisspeptin. Gq inhibition repressed kisspeptin-induced invasiveness of glioblastoma cells (Figure 3A).

Kisspeptin is known to increase IP3 production via KISS1RGq-PLC pathway (38). To examine whether kisspeptin-activated KISS1R requires phospholipase C (PLC) in the invasiveness, U87-MG cells were pre-treated with PLC inhibitor D609 or U73122, and then treated with kisspeptin. PLC inhibition blocked kisspeptin-induced invasiveness (Figure 3B). Therefore, our data indicate that kisspeptin activation of KISS1R-Gq-PLC pathway promotes glioblastoma cell invasiveness.

Kisspeptin induces metastatic abilities of glioblastoma cells by activating PKC. PKC activation promotes glioblastoma cell invasiveness $(39,40)$. Because kisspeptin activates PKC, we next examined whether kisspeptin activation of PKC leads to metastatic abilities of glioblastoma cells. When cells were pretreated with PKC inhibitor, bisindolylmaleimide III at $20 \mathrm{nM}$ for $1 \mathrm{~h}$ and then treated with kisspeptin for another $23 \mathrm{~h}, \mathrm{PKC}$ inhibition blocked kisspeptin-induced invasiveness (Figure $4 \mathrm{~A})$. Next, PKC $\alpha / \beta$ phosphorylation status was examined. Kisspeptin increased PKC $\alpha / \beta$ phosphorylation, when cells were serum-starved for $3 \mathrm{~h}$ and then treated with kisspeptin for another 15 min (Figure 4B). Moreover, kisspeptin increased $\mathrm{PKC} \alpha / \beta$ phosphorylation even when cells were cultured in serum-contained medium and treated with kisspeptin for 15 min (Figure 4B). Thus, kisspeptin activates PKC $\alpha / \beta$, although serum factors may attenuate kisspeptin effect on $\mathrm{PKC} \alpha / \beta$ phosphorylation. In addition, bisindolylmaleimide III blocked kisspeptin activation of PKC $\alpha / \beta$ phosphorylation (Figure 4C). 

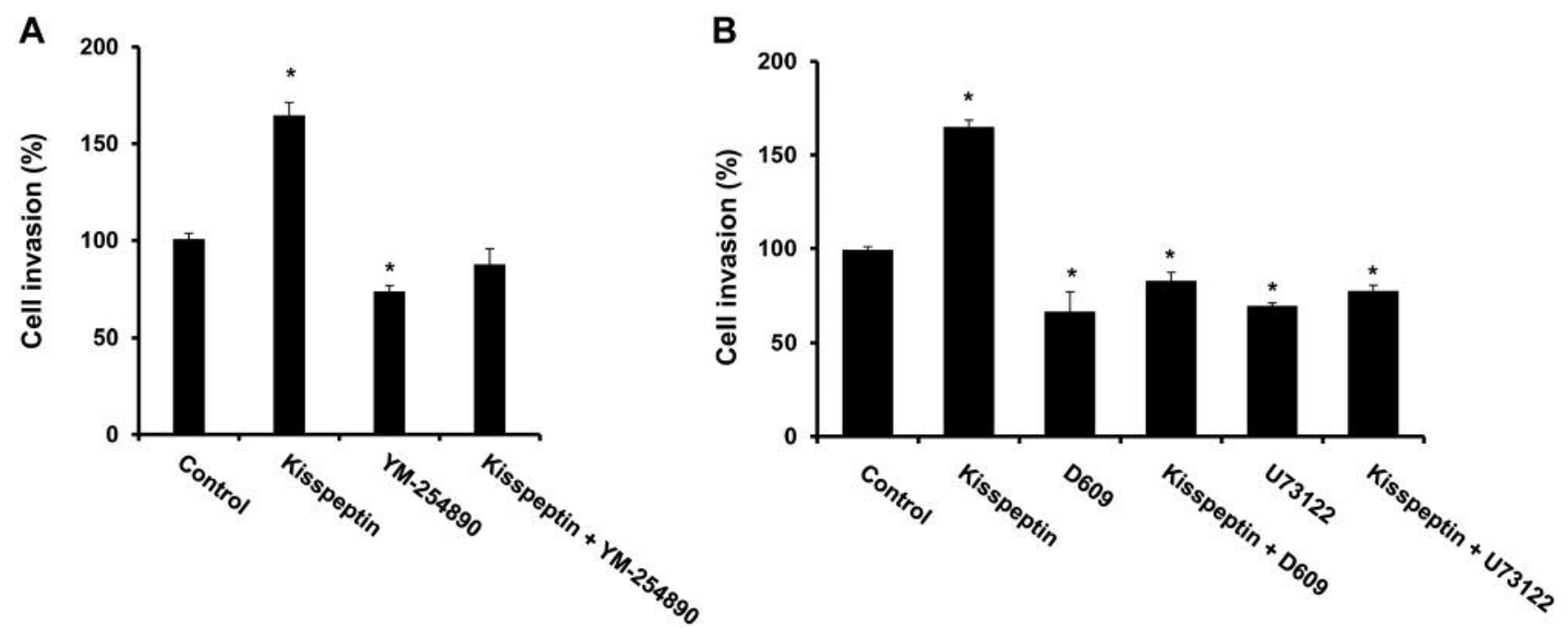

Figure 3. Kisspeptin induces brain tumor cell invasiveness via the Gq-PLC pathway. (A) Gq inhibitor, YM-254890 blocked kisspeptin-induced brain tumor cell invasion. (B) PLC inhibitors, D609 and U73122 blocked kisspeptin-induced brain tumor cell invasion. *p<0.05.

A

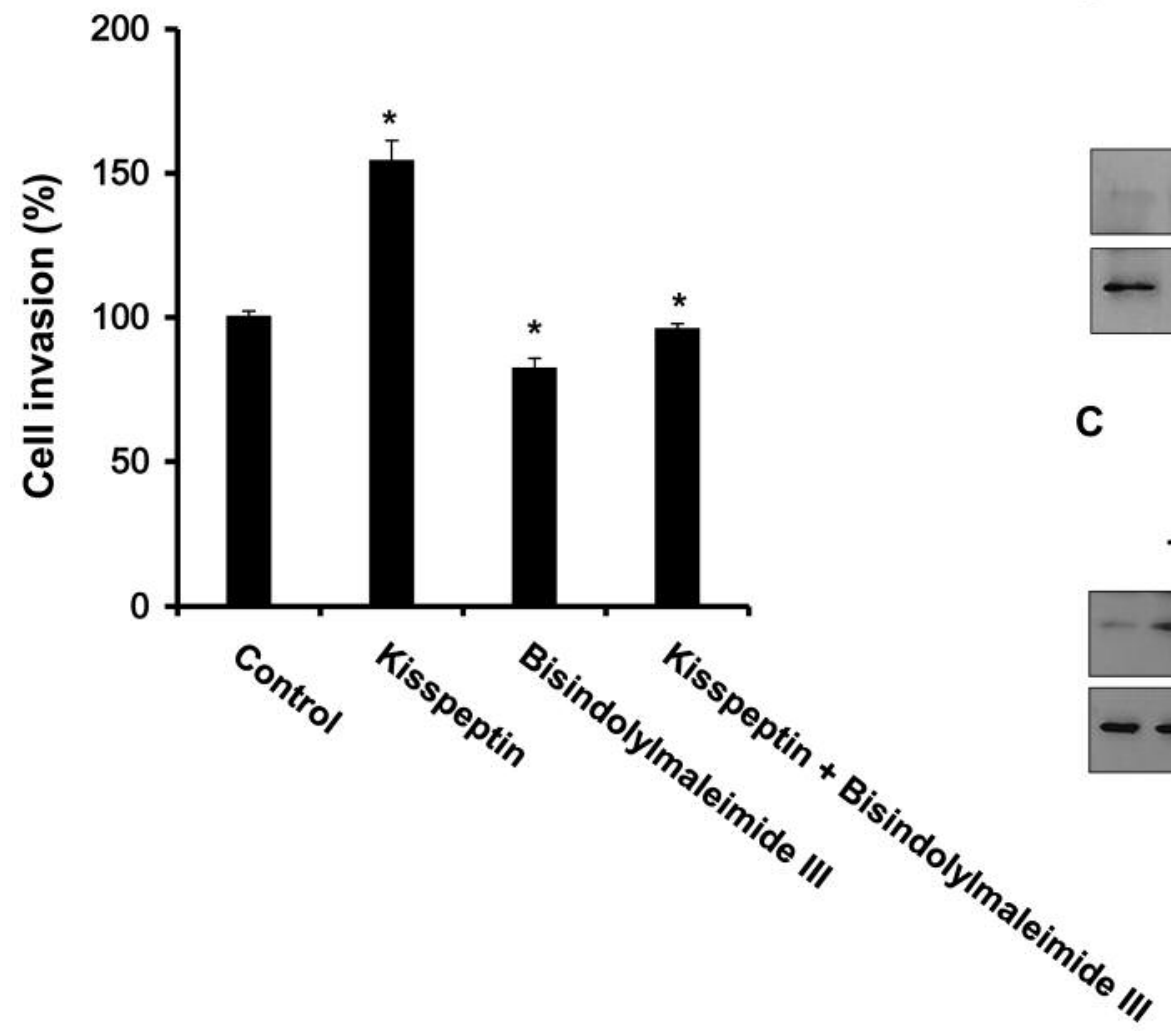

B
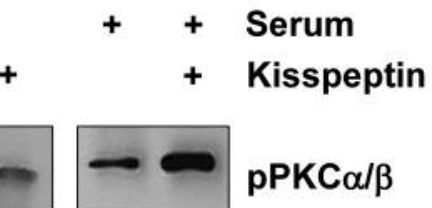

- Actin

Figure 4. Kisspeptin-induced brain tumor cell invasion requires PKC activation. (A) PKC inhibitor, bisindolylmaleimide III blocked kisspeptininduced brain tumor cell invasion. ${ }^{*} p<0.05$. (B) Kisspeptin induced PKC $\alpha / \beta$ phosphorylation in both serum-starved and serum-contained conditions. (C) PKC inhibitor, bisindolylmaleimide III inhibited kisspeptin-induced PKC $\alpha / \beta$ phosphorylation. 
Thus, kisspeptin activation of PKC is crucial for the invasiveness of glioblastoma cells.

\section{Discussion}

This study is the first study to report a role of kisspeptin in brain tumor. Our data showed that kisspeptin promotes invasiveness of glioblastoma cells by inducing KISS1R-GqPLC-PKC signaling.

Glioblastoma cell lines conventionally used for in vitro studies do not express endogenous kisspeptin while expressing its endogeneous receptor, KISS1R. Kisspeptin expression in glioblastoma cell lines may be shut down by epigenetic mechanisms or mutations. Epigenetic regulation of either KISS1 or KISS1R has been reported in various biological conditions $(41,42)$. Meanwhile, TCGA and cBioPortal show no mutations of KISS1 in glioblastoma. However, it is still unknown whether KISS1 gene expression is epigenetically repressed in glioblastoma. Therefore, it is expected that future studies will address an epigenetic regulation of KISS1 gene expression.

Our study aiming to investigate the role of kisspeptin in glioblastoma, explored a conventional KISS1R-mediated intracellular signaling pathway. In glioblastoma cells, kisspeptin activated Gq-PLC pathway via KISS1R. Moreover, glioblastoma cells required PKC activation in kisspeptin-promoted invasiveness. This finding is in line with a recent report that Gq-PLC-PKC promotes cancer cell invasiveness $(17,39,40)$.

Our data showed that exogenous kisspeptin promotes the invasiveness of glioblastoma cells. This finding raises a question of whether endogenous kisspeptin affects local metastasis of glioblastoma. If kisspeptin is expressed in cells near glioma cells, it may promote the invasiveness of glioma cells. In addition, circadian rhythm and/or dietary conditions may alter glioma cell invasiveness via endogenous kisspeptin. Circadian rhythm is known to promote glioblastoma cell proliferation and migration $(43,44)$. Thus, it is important to find kisspeptinexpressing cells in microenvironment of glioblastoma.

Kisspeptin has been known to repress invasiveness of various cancer cell types $(17,18,20)$. In this study, we presented opposite results; kisspeptin was shown to induce glioblastoma invasiveness. We still do not know how kisspeptin has two different roles in different cancer cell types. Future studies will address whether a blockade of kisspeptin-KISS1R signaling inhibits the invasiveness of glioblastoma cells. These studies may help elucidate how the tumor microenvironment regulates glioblastoma metastasis and potentially provide a therapeutic target.

\section{Conflicts of Interest}

The Authors declare no potential conflicts of interest.

\section{Authors' Contributions}

Kim TH conducted experiments and analysed data. Yoon JH performed experiments. Cho SG designed experiments and wrote the manuscript.

\section{Acknowledgements}

This study was supported by the Korea National University of Transportation in 2018 and and by the Basic Science Research Program through the National Research Foundation of Korea funded by the Ministry of Science, ICT and Future Planning (grant no. NRF-2014R1A1A1035831).

\section{References}

1 Gimple RC, Bhargava S, Dixit D and Rich JN: Glioblastoma stem cells: Lessons from the tumor hierarchy in a lethal cancer. Genes Dev 33(11-12): 591-609, 2019. PMID: 31160393. DOI: $10.1101 / \operatorname{gad} .324301 .119$

2 Zanders ED, Svensson F and Bailey DS: Therapy for glioblastoma: Is it working? Drug Discov Today 24(5): 1193-1201, 2019. PMID: 30878561. DOI: 10.1016/j.drudis.2019.03.008

3 Louis DN, Perry A, Reifenberger G, von Deimling A, FigarellaBranger D, Cavenee WK, Ohgaki H, Wiestler OD, Kleihues P and Ellison DW: The 2016 world health organization classification of tumors of the central nervous system: A summary. Acta Neuropathol 131(6): 803-820, 2016. PMID: 27157931. DOI: 10.1007/s00401-016-1545-1

4 Ricard D, Idbaih A, Ducray F, Lahutte M, Hoang-Xuan K and Delattre JY: Primary brain tumours in adults. Lancet 379(9830): 1984-1996, 2012. PMID: 30060998. DOI: 10.1016/S01406736(18)30990-5

5 Minniti G, Lombardi G and Paolini S: Glioblastoma in elderly patients: Current management and future perspectives. Cancers (Basel) 11(3), 2019. PMID: 30857221. DOI: 10.3390/cancers 11030336

6 Lukas RV, Wainwright DA, Ladomersky E, Sachdev S, Sonabend AM and Stupp R: Newly diagnosed glioblastoma: A review on clinical management. Oncology (Williston Park) 33(3): 91-100, 2019. PMID: 30866031.

7 Honea N: End-of-life care for patients with glioma. Semin Oncol Nurs 34(5): 553-568, 2018. PMID: 30424921. DOI: 10.1016/j.soncn.2018.10.013

8 Mooney J, Bernstock JD, Ilyas A, Ibrahim A, Yamashita D, Markert JM and Nakano I: Current approaches and challenges in the molecular therapeutic targeting of glioblastoma. World Neurosurg, 2019. PMID: 31152883. DOI: 10.1016/j.wneu.2019.05.205

9 Daniel P, Sabri S, Chaddad A, Meehan B, Jean-Claude B, Rak J and Abdulkarim BS: Temozolomide induced hypermutation in glioma: Evolutionary mechanisms and therapeutic opportunities. Front Oncol 9: 41, 2019. PMID: 30778375. DOI: 10.3389/fonc. 2019.00041

10 Tomiyama A and Ichimura K: Signal transduction pathways and resistance to targeted therapies in glioma. Semin Cancer Biol, 2019. PMID: 30685341. DOI: 10.1016/j.semcancer.2019.01.004

11 Lathia JD, Mack SC, Mulkearns-Hubert EE, Valentim CL and Rich JN: Cancer stem cells in glioblastoma. Genes Dev 29(12): 12031217, 2015. PMID: 26109046. DOI: 10.1101/gad.261982.115 
12 Miyata H, Ashizawa T, Iizuka A, Kondou R, Nonomura C, Sugino T, Urakami K, Asai A, Hayashi N, Mitsuya K, Nakasu Y, Yamaguchi K and Akiyama Y: Combination of a stat3 inhibitor and an mtor inhibitor against a temozolomide-resistant glioblastoma cell line. Cancer Genomics Proteomics 14(1): 8391, 2017. PMID: 28031240 . DOI: $10.21873 / \mathrm{cgp} .20021$

$13 \mathrm{Ke} \mathrm{R}$, Ma X and Lee LTO: Understanding the functions of kisspeptin and kisspeptin receptor (kiss1r) from clinical case studies. Peptides, 2018. PMID: 30339828. DOI: 10.1016/j.peptides.2018.09.007

14 Mills EGA, Dhillo WS and Comninos AN: Kisspeptin and the control of emotions, mood and reproductive behaviour. J Endocrinol 239(1): R1-R12, 2018. PMID: 30306845. DOI: 10.1530/JOE-18-0269

15 Evans MC and Anderson GM: Integration of circadian and metabolic control of reproductive function. Endocrinology 159(11): 3661-3673, 2018. PMID: 30304391. DOI: 10.1210/en.2018-00691

16 Aguirre RS and Eugster EA: Central precocious puberty: From genetics to treatment. Best Pract Res Clin Endocrinol Metab 32(4): 343-354, 2018. PMID: 30086862. DOI: 10.1016/j.beem. 2018.05.008

17 Guzman S, Brackstone M, Radovick S, Babwah AV and Bhattacharya MM: Kiss1/kiss1r in cancer: Friend or foe? Front Endocrinol (Lausanne) 9: 437, 2018. PMID: 30123188. DOI: 10.3389/fendo.2018.00437

18 Jabeen S, Qureshi MZ, Javed Z, Iqbal MJ, Ismail M and Farooqi AA: Kisspeptin mediated signaling in cancer. Curr Top Med Chem 16(22): 2471-2476, 2016. PMID: 26873190. DOI: 10.2174/1568026616666160212123309

19 Abreu AP and Kaiser UB: Pubertal development and regulation. Lancet Diabetes Endocrinol 4(3): 254-264, 2016. PMID: 26852256. DOI: $10.1016 / \mathrm{S} 2213-8587(15) 00418-0$

20 Cho SG, Li D, Tan K, Siwko SK and Liu M: Kiss1 and its gprotein-coupled receptor gpr54 in cancer development and metastasis. Cancer Metastasis Rev 31(3-4): 585-591, 2012. PMID: 22692479. DOI: 10.1007/s10555-012-9367-7

21 Prague JK and Dhillo WS: Potential clinical use of kisspeptin. Neuroendocrinology 102(3): 238-245, 2015. PMID: 26277870. DOI: $10.1159 / 000439133$

22 Clarke H, Dhillo WS and Jayasena CN: Comprehensive review on kisspeptin and its role in reproductive disorders. Endocrinol Metab (Seoul) 30(2): 124-141, 2015. PMID: 26194072. DOI: 10.3803/EnM.2015.30.2.124

23 Papaoiconomou E, Msaouel P, Makri A, Diamanti-Kandarakis E and Koutsilieris M: The role of kisspeptin/gpr54 in the reproductive system. In Vivo 25(3): 343-354, 2011. PMID: 21576407.

24 Silveira LFG, Teles MG, Trarbach EB and Latronico AC: Role of kisspeptin/gpr54 system in human reproductive axis. Front Horm Res 39: 13-24, 2010. PMID: 20389082. DOI: $10.1159 / 000312689$

25 Ishikawa K, Tanaka A, Kogame A, Watanabe T, Tagawa Y and Matsui H: Usefulness of pharmacokinetic/efficacy analysis of an investigational kisspeptin analog, tak-448, in quantitatively evaluating anti-tumor growth effect in the rat vcap androgensensitive prostate cancer model. Eur J Pharmacol 828: 126-134, 2018. PMID: 29580912. DOI: 10.1016/j.ejphar.2018.03.032

26 Tanaka A, Nakata D, Masaki T, Kusaka M, Watanabe T and Matsui H: Evaluation of pharmacokinetics/pharmacodynamics and efficacy of one-month depots of tak-448 and tak-683, investigational kisspeptin analogs, in male rats and an androgendependent prostate cancer model. Eur J Pharmacol 822: 138146, 2018. PMID: 29355559. DOI: 10.1016/j.ejphar.2018.01.012

27 Moriya Y, Kogame A, Tagawa Y, Morohashi A, Kondo T, Asahi $\mathrm{S}$ and Benet LZ: The enhancement of subcutaneous first-pass metabolism causes non-linear pharmacokinetics of tak-448 after a single subcutaneous administration to rats. Drug Metab Dispos, 2019. PMID: 31201213. DOI: 10.1124/dmd.119.087148

28 Cho SG, Yi Z, Pang X, Yi T, Wang Y, Luo J, Wu Z, Li D and Liu M: Kisspeptin-10, a kiss1-derived decapeptide, inhibits tumor angiogenesis by suppressing sp1-mediated vegf expression and fak/rho gtpase activation. Cancer Res 69(17): 7062-7070, 2009. PMID: 19671799. DOI: 10.1158/00085472.CAN-09-0476

29 Cho SG, Wang Y, Rodriguez M, Tan K, Zhang W, Luo J, Li D and Liu M: Haploinsufficiency in the prometastasis kiss1 receptor gpr54 delays breast tumor initiation, progression, and lung metastasis. Cancer Res 71(20): 6535-6546, 2011. PMID: 21852382. DOI: 10.1158/0008-5472.CAN-11-0329

30 Goertzen CG, Dragan M, Turley E, Babwah AV and Bhattacharya $\mathrm{M}$ : Kiss1r signaling promotes invadopodia formation in human breast cancer cell via beta-arrestin2/erk. Cell Signal 28(3): 165-176, 2016. PMID: 26721186. DOI: 10.1016/j.cellsig. 2015.12 .010

31 Tian J, Al-Odaini AA, Wang Y, Korah J, Dai M, Xiao L, Ali S and Lebrun JJ: Kiss1 gene as a novel mediator of tgfbetamediated cell invasion in triple negative breast cancer. Cell Signal 42: 1-10, 2018. PMID: 28988968. DOI: 10.1016/j.cellsig.2017.10.002

32 Matsui H, Masaki T, Akinaga Y, Kiba A, Takatsu Y, Nakata D, Tanaka A, Ban J, Matsumoto S, Kumano S, Suzuki A, Ikeda Y, Yamaguchi M, Watanabe $\mathrm{T}$, Ohtaki $\mathrm{T}$ and Kusaka $\mathrm{M}$ : Pharmacologic profiles of investigational kisspeptin/metastin analogues, tak-448 and tak-683, in adult male rats in comparison to the gnrh analogue leuprolide. Eur J Pharmacol 735: 77-85, 2014. PMID: 24747751. DOI: 10.1016/j.ejphar.2014.03.058

33 MacLean DB, Matsui H, Suri A, Neuwirth R and Colombel M: Sustained exposure to the investigational kisspeptin analog, tak448 , down-regulates testosterone into the castration range in healthy males and in patients with prostate cancer: Results from two phase 1 studies. J Clin Endocrinol Metab 99(8): E14451453, 2014. PMID: 24762108. DOI: 10.1210/jc.2013-4236

34 Corno $\mathrm{C}$ and Perego P: Kiss 1 in regulation of metastasis and response to antitumor drugs. Drug Resist Updat 42: 12-21, 2019. PMID: 30776659. DOI: 10.1016/j.drup.2019.02.001

35 Ohtaki T, Shintani Y, Honda S, Matsumoto H, Hori A, Kanehashi K, Terao Y, Kumano S, Takatsu Y, Masuda Y, Ishibashi Y, Watanabe T, Asada M, Yamada T, Suenaga M, Kitada C, Usuki S, Kurokawa T, Onda H, Nishimura O and Fujino M: Metastasis suppressor gene kiss-1 encodes peptide ligand of a g-protein-coupled receptor. Nature 411(6837): 613617, 2001. PMID: 11385580. DOI: $10.1038 / 35079135$

36 Muir AI, Chamberlain L, Elshourbagy NA, Michalovich D, Moore DJ, Calamari A, Szekeres PG, Sarau HM, Chambers JK, Murdock P, Steplewski K, Shabon U, Miller JE, Middleton SE, Darker JG, Larminie CG, Wilson S, Bergsma DJ, Emson P, Faull R, Philpott KL and Harrison DC: Axor12, a novel human $\mathrm{g}$ protein-coupled receptor, activated by the peptide kiss-1. J Biol Chem 276(31): 28969-28975, 2001. PMID: 11387329. DOI: $10.1074 /$ jbc.M102743200 
37 Kotani M, Detheux M, Vandenbogaerde A, Communi D, Vanderwinden JM, Le Poul E, Brezillon S, Tyldesley R, SuarezHuerta N, Vandeput F, Blanpain C, Schiffmann SN, Vassart G and Parmentier M: The metastasis suppressor gene kiss-1 encodes kisspeptins, the natural ligands of the orphan $g$ protein-coupled receptor gpr54. J Biol Chem 276(37): 34631-34636, 2001. PMID: 11457843. DOI: $10.1074 /$ jbc.M104847200

38 Becker JA, Mirjolet JF, Bernard J, Burgeon E, Simons MJ, Vassart G, Parmentier M and Libert F: Activation of gpr54 promotes cell cycle arrest and apoptosis of human tumor cells through a specific transcriptional program not shared by other gq-coupled receptors. Biochem Biophys Res Commun 326(3): 677-686, 2005. PMID: 15596153. DOI: 10.1016/j.bbrc.2004.11.094

39 do Carmo A, Balca-Silva J, Matias D and Lopes MC: Pkc signaling in glioblastoma. Cancer Biol Ther 14(4): 287-294, 2013 PMID: 23358475. DOI: $10.4161 /$ cbt.23615

40 Nomura N, Nomura M, Sugiyama K and Hamada J: Src regulates phorbol 12-myristate 13-acetate-activated pkc-induced migration via $\mathrm{cas} / \mathrm{crk} / \mathrm{rac} 1$ signaling pathway in glioblastoma cells. Int J Mol Med 20(4): 511-519, 2007. PMID: 17786281.

41 Kostadima L, Pentheroudakis G and Pavlidis N: The missing kiss of life: Transcriptional activity of the metastasis suppressor gene kiss 1 in early breast cancer. Anticancer Res 27(4B): 2499-2504, 2007. PMID: 17695545.
42 Motti ML and Meccariello R: Minireview: The epigenetic modulation of kiss 1 in reproduction and cancer. Int J Environ Res Public Health 16(14), 2019. PMID: 31336647. DOI: 10.3390/ijerph16142607

43 Zhou L, Tang H, Wang F, Chen L, Ou S, Wu T, Xu J and Guo K: Bioinformatics analyses of significant genes, related pathways and candidate prognostic biomarkers in glioblastoma. Mol Med Rep 18(5): 4185-4196, 2018. PMID: 30132538. DOI: 10.3892/ mmr.2018.9411

$44 \mathrm{Yu}$ M, Li W, Wang Q, Wang Y and Lu F: Circadian regulator nr1d2 regulates glioblastoma cell proliferation and motility. Oncogene 37(35): 4838-4853, 2018. PMID: 29773903. DOI: 10.1038/s41388-018-0319-8
Received November 6, 2019

Revised November 13, 2019

Accepted November 25, 2019 